\title{
Socio-Economic Conditions and Quality of Life in the Tribal Areas of Orissa with Special Reference to Mayurbhanj District
}

\author{
Dr N.C. Jana ${ }^{\dagger *}$ and Prasanta Kumar Ghosh ${ }^{\grave{ }}$
}

\section{Abstract}

Orissa, being socio-economically backward but sound in traditional culture, is one of the important states in eastern India. Out of 30 districts, nine are considered as tribal districts (according to Location Quotient value), and, of the total population (41,947,358 in 2011), a significant share (22.1\%) goes to tribal people $(8,145,081$ in 2011$)$. They are also one of the most backward and geographically isolated communities. Their lifestyle and economy is confined to the direct utilisation of natural resources, pre-agricultural level of technology and specific indigenous type of work. Now with the emergence of industry and market economy, the age-old relationship between tribes and nature has been disturbed. Keeping this in backdrop, the present study tries to explore the changing scenario of socio-economic condition in the tribal areas of Orissa. In this regard, various socioeconomic indicators have been analysed and compared for representing district-level patterns of quality of life and finding out the variation among the primitive tribal households in the study area. In addition, Mayurbhanj has also been taken as a case study to represent the socio-economic condition and quality of life at the block level. It may be pointed out in this context that out of 30 districts in Orissa, according to Location Quotient value Mayurbhanj is the highest tribalconcentrated district. The overall objective of this study is to obtain a better understanding of the disparities and variations in socio-economic status in Orissa as well as in Mayurbhanj and also find out some remedial measures to overcome the problems to bring the primitive tribal community in the mainstream of the society. From the analysis of the health-related indicators, it is clear from the analysis that the quality of life in the district has improved remarkably over the years, but socioeconomic disparities in terms of caste and gender continue to be a major problem mostly in tribal and backward areas.

Key words: Schedule Tribe, Primitive tribes, Location Quotient, Socio-economic disparity, Quality of life, Mayurbhanj District, Orissa

\footnotetext{
${ }^{+}$Associate Professor, Department of Geography, The University of Burdwan, Burdwan-713104, email: jana.narayan@gmail.com; *corresponding author

IPPD Student, Department of Geography, The University of Burdwan, Burdwan-713104, email: prasantaghosh005@gmail.com

(C) 2015 Jana and Ghosh. This is an Open Access article distributed under the terms of the Creative Commons Attribution License (http://creativecommons.org/licenses/by/2.0), which permits unrestricted use, distribution, and reproduction in any medium, provided the original work is properly cited.
} 


\section{Introduction}

The tribal ${ }^{1}$ societies in India are considered as the weakest sections of the population in terms of common socio-economic and demographic factors such as poverty, illiteracy, lack of developmental facilities and adequate primary health facilities (Thakur et al., 1991; Basu, 1994). For many decades, 'growth with equity and social justice' has remained on the development agenda of developing countries, but from the historical past, Indian society suffers from substantial disparity in education, employment, and income based on caste and ethnicity (Desai and Kulkarni, 2008). According to the Ministry of Tribal Affairs, Government of India, over 84 million people belonging to 698 communities are identified as members of Scheduled Tribes (ST) in India (Agarwal, 2013). Among the 29 states in India, Orissa ${ }^{2}$ (presently known as Odisha), being socio-economically backward and culturally sound, occupies a unique place in the tribal map of the country having largest number of tribal communities (62 tribes including 13 primitive tribes) with a population of 9.59 million constituting $22.86 \%$ of state's population and $9.17 \%$ of the total tribal population of the country (Census of India, 2011). They mainly live in isolated areas and far away from the modern civilization with their traditional values, customs, beliefs and myth. Out of 30 districts in Orissa, nine are considered as tribal districts (according to Location Quotient value). Mayurbhanj is one of them. The current research aims to show the patterns of socioeconomic conditions of tribals in Orissa with respect to three indicators or variables, that is, health, education and economy. We have also tried to compare block-wise variations (spatial disparity) of socio-economic conditions between tribes and non-tribes (social disparity) and male-female population (gender disparity)

\footnotetext{
${ }^{1}$ Article 366 (25) of the Constitution of India refers to Scheduled Tribes as those communities, who are scheduled in accordance with Article 342 of the Constitution. The essential characteristics, first laid down by the Lokur Committee, for a community to be identified as Scheduled Tribes are: (a) Indications of primitive traits; (b) Distinctive culture; (c) Shyness of contact with the community at large; (d) Geographical isolation; and (e)
}

in Mayurbhanj. In this paper, we gave emphasis on: (i) education as it is an important component of human development which indicates a person's productivity and income-earning potential by imparting basic as well as specialised skills (DHDR, Mayurbhanj 2011), (ii) health as the healthcare system in this state has improved remarkably over the years, communicable and nutrition related diseases continue to be a major problem mostly in the tribal and backward areas (State of the Environment Report, Orissa 2007), and (iii) economy as economic growth is a necessary condition for human development and it is one of the major components to satisfy the basic needs of life.

\section{Study Area}

Total geographical area of Mayurbhanj as well as the study area (Fig. 1) is 10,418 sq. km and extends from $21^{\circ} 16^{\prime} \mathrm{N}$ to $22^{\circ} 34^{\prime} \mathrm{N}, 85^{\circ} 42^{\prime} \mathrm{E}$ to $87^{\circ} 11^{\prime} \mathrm{E}$. Before India's independence, Mayurbhanj was a princely state, ruled by the Mayurs and Bhanjas since the Ninth Century A.D. They ruled continuously for more than 1000 years. It was the last feudal state to be annexed with Orissa on January 1949 and became the largest district in Orissa. It is a tribal-dominated border district in northern Orissa with a rich tradition and vibrant culture. The Similipal forest is known for its biodiversity and natural panorama. For administrative convenience, the district has been organised into four subdivisions, namely, Panchpir, Bamanghaty, Baripada and Kaptipada. There are 9 tehsils and 28 police stations. The district is divided into 26 Community Development Blocks, which comprise 382 Gram Panchayats and 3,952 villages. Three distinct topographical formations are found in the district. At the centre, there are hills and lesser elevations running from north to south. These hills divide the plains into two

Backwardness. The Primitive tribal communities have been identified by the Govt. of India on the basis of (a) pre agricultural level of technology, (b) extremely low level of literacy; and (c) small, stagnant or diminishing population. "Bhumija", "Kolhas" and "Santals"are the major tribes of Mayurbhanj district.

${ }^{2}$ In this research, we use as Orissa. 
parts: eastern and western. The eastern part, which comprises Kaptipada and Baripada subdivisions slopes gradually towards the sea. A number of hill streams pass through this region.
On the western side, there are many rocky mounds and hills, for which the landscape is marked by rolling topography (DHDR, Mayurbhanj 2011) (Fig. 1).

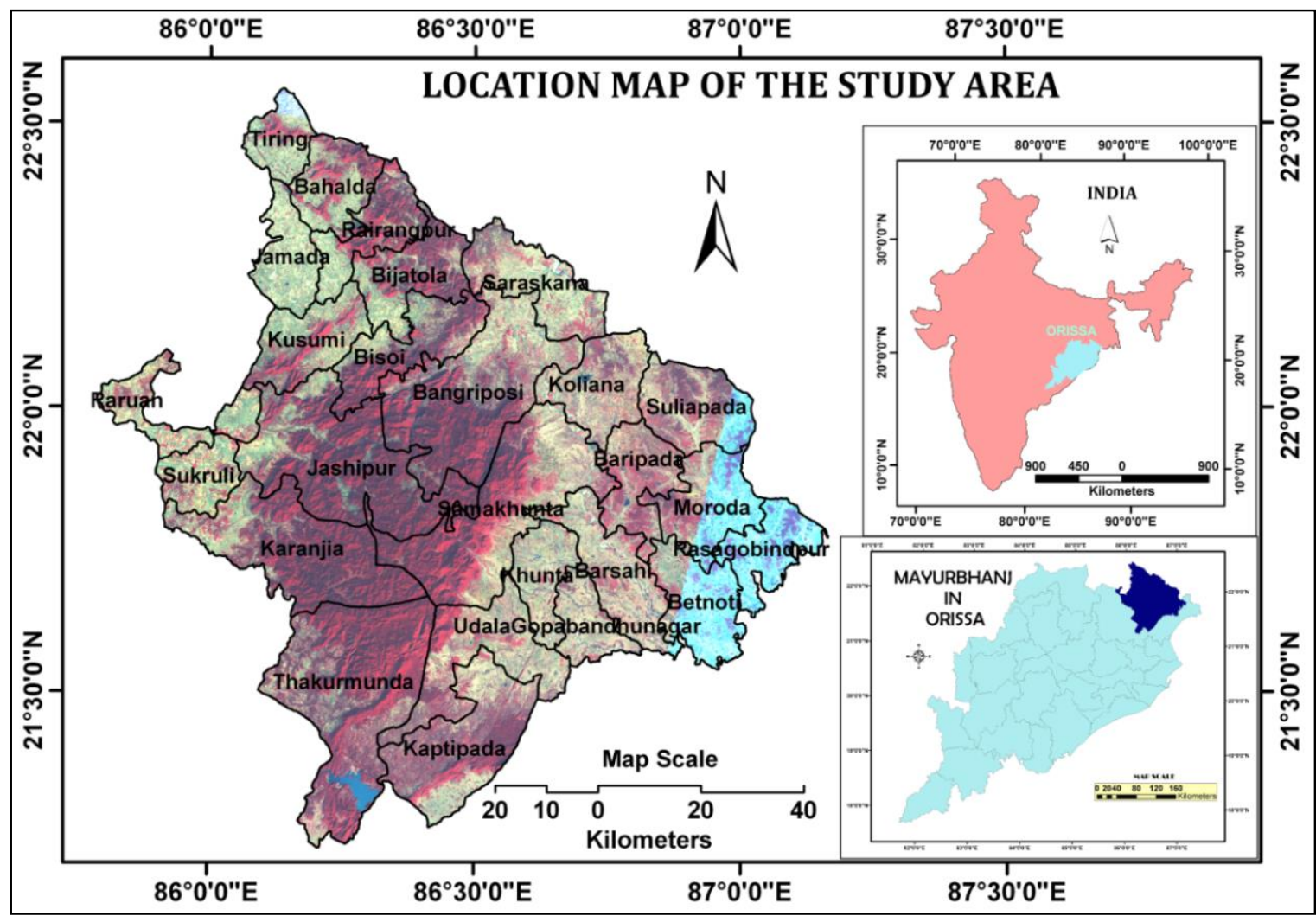

Fig. 1: Blocks and Physiography of Mayurbhanj, Orissa (Source: Landsat ETM data \&District Website)

\section{Rationale: Mayurbhanj as a Study Area}

Orissa has the second largest tribal population in India next to Madhya Pradesh. In percentage, it has the highest tribal concentration in its population. As per 2011 Census, the tribal population is $22.86 \%$, although district-wise it varies from $58.7 \%$ (Mayurbhanj) to $0.4 \%$ (Puri). With regard to socio-economic conditions, there are significant disparities in the state among the districts. In this research, an attempt has been made to investigate the present socio-economic conditions and spatial disparity at block levels in terms of caste and gender in Mayurbhanj district, as this district has the second highest proportion of STs (56.6 per cent) and highest concentration of schedule tribe population (highest Location Quotient value), and it is the only district in Orissa, where more than $70 \%$ (73.42\%) out of school children are STs (Fig. 2). Objectives
The overall objective of this study is to obtain a better understanding of the present conditions and disparities in socio-economic status in Mayurbhanj, Orissa. This study includes:

- concentration of tribes in Mayurbhanj and Orissa;

- analysis of present socio-economic conditions at block level;

- intra-regional disparities among different communities and gender;

- identification of probable factors responsible for such variations,

- analysis of the dominant economic activity and its level in different blocks; and

- remedial measures required to overcome the problems of socio economic as well as human development. 


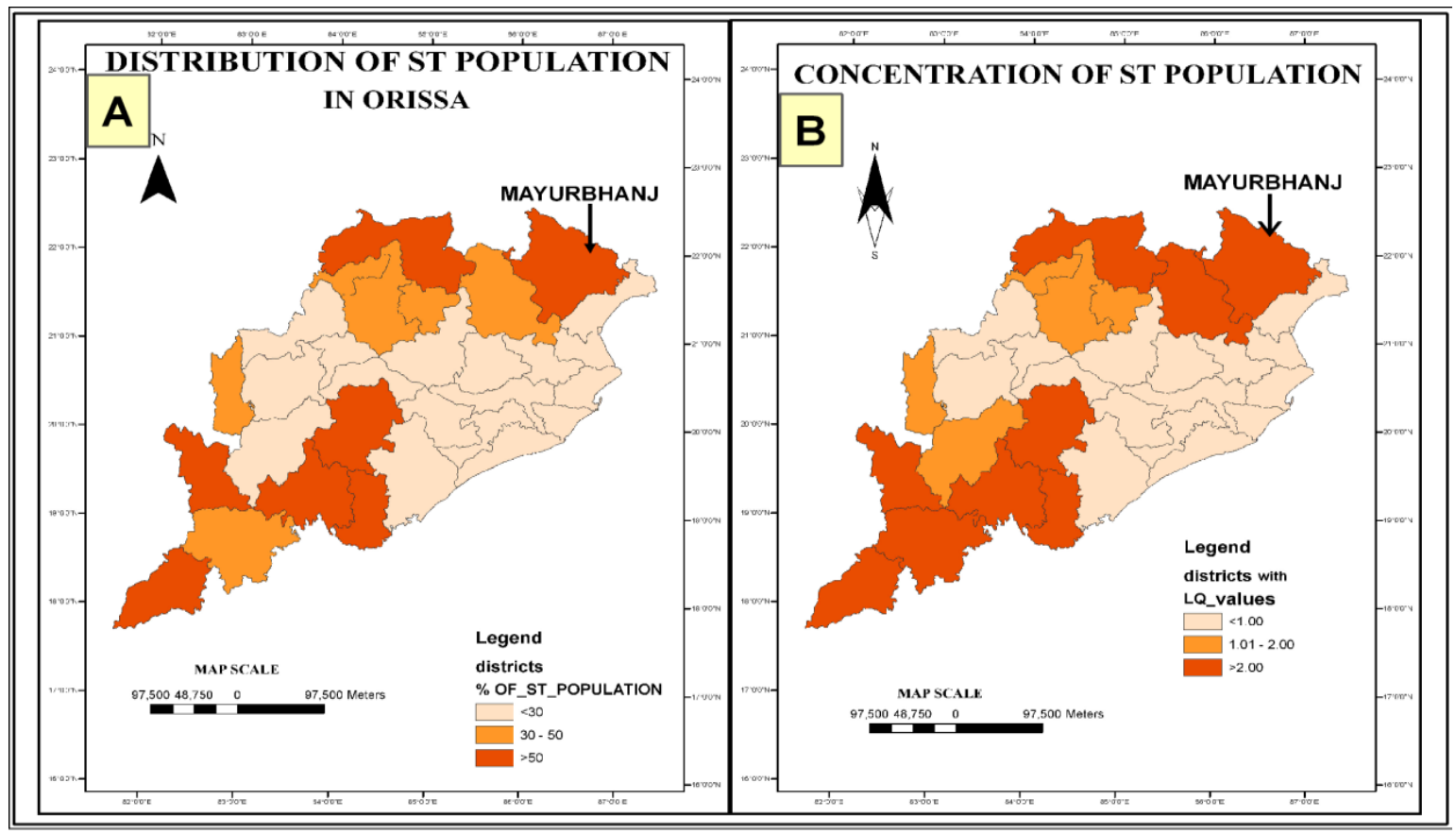

Fig.-2A \& 2B: District-wise Distribution \& Concentration of Tribes in Orissa (Data Source: Census of India 2011, Calculation \& Mapping by the Authors)

\section{Data Base and Methodology}

The research methods followed in this work include consultation of literature, data collection from secondary sources, statistical analysis, and preparation of maps. From some available books, reports and papers, we have retrieved the basic ideas about the study area. Secondary data are obtained from (i) District Human Development Report, Mayurbhanj: 2011 (ii) District Statistical Handbook, Mayurbhanj: 2009 (iii) Odisha Primary Education Programme Authority (http://www.opepa.in) (iv) Odisha Government Portal (http://www.odisha.gov.in), (v) Department of School \& Mass Education (http://www.odisha.gov.in/schooleducation), (vi) ST \& SC Development, Minorities \& Backward Classes Welfare Department (http://www.stscodisha.gov.in), (vii) SC \& ST Research and Training Institute, Bhubaneswar, (viii) Integrated Tribal Development Authority, Baripada, (ix) District Statistical Office, Baripada, Mayurbhanj, (x) Census of India: 2001 \& 2011 (xi) District Level Household and Facility survey of Orissa or DLHS-3, and (xii) Bulletin of Indian Council of Medical Research: 2009. For better understanding of the socio-economic conditions and disparities, we use different statistical techniques like (a) Location Quotient; (b) Sophers' Disparity Index; (c) Nelson's Method to identify dominant functions; (d) Ranking Method of constructing Composite Index, and (e) Co-efficient of Equality in Education, etc. Physiographical map have been prepared by mosaicing satellite images in Erdas Imagine v.9.0.Other maps have been prepared based on secondary data using Arc-GIS software v.9.3. Diagrams are prepared with the help of Microsoft Office Excel v.2007.

\section{Discussion and Analysis}

\section{Spatial Distribution of Scheduled Tribes in Mayurbhanj}

Among the 30 districts of Orissa, Mayurbhanj has the highest concentration of tribes (Location Quotient value is 2.56). Among 26 Community Development Blocks of Mayurbhanj, four blocks (Suliapada, Betnoti, Moroda and Barsahi) have less than 50 percent tribal population while seven blocks (Tiring, Jamada, Bijatola, Baripada, Khunta, Udala and Thakurmunda) have more than 70 percent tribal population with respect to its total population (Fig. 3/A). Using the value of Location Quotient, we identified six blocks as 
tribal dominated. The map reveals the following spatial pattern.

- Higher level of concentration (LQ value is >1.2) - Tiring, Jamada, Bijatola, Khunta, Udala and Thakurmunda.

- Medium level of concentration (LQ value is 1.00-1.20) - Kusumi, Bisoi,

Bangriposi, Koliana, Baripada, Samakhunta, Karanjia, Sukruli, Jashipur and Kaptipada.

- Lower level of concentration (LQ value is $<1.00$ ) - Bahalda, Rairangpur, Raruan, Gopabandhu Nagar, Betnoti, Barsahi, Rasagobindpur, Maroda and Suliapada (Fig. 3/B).

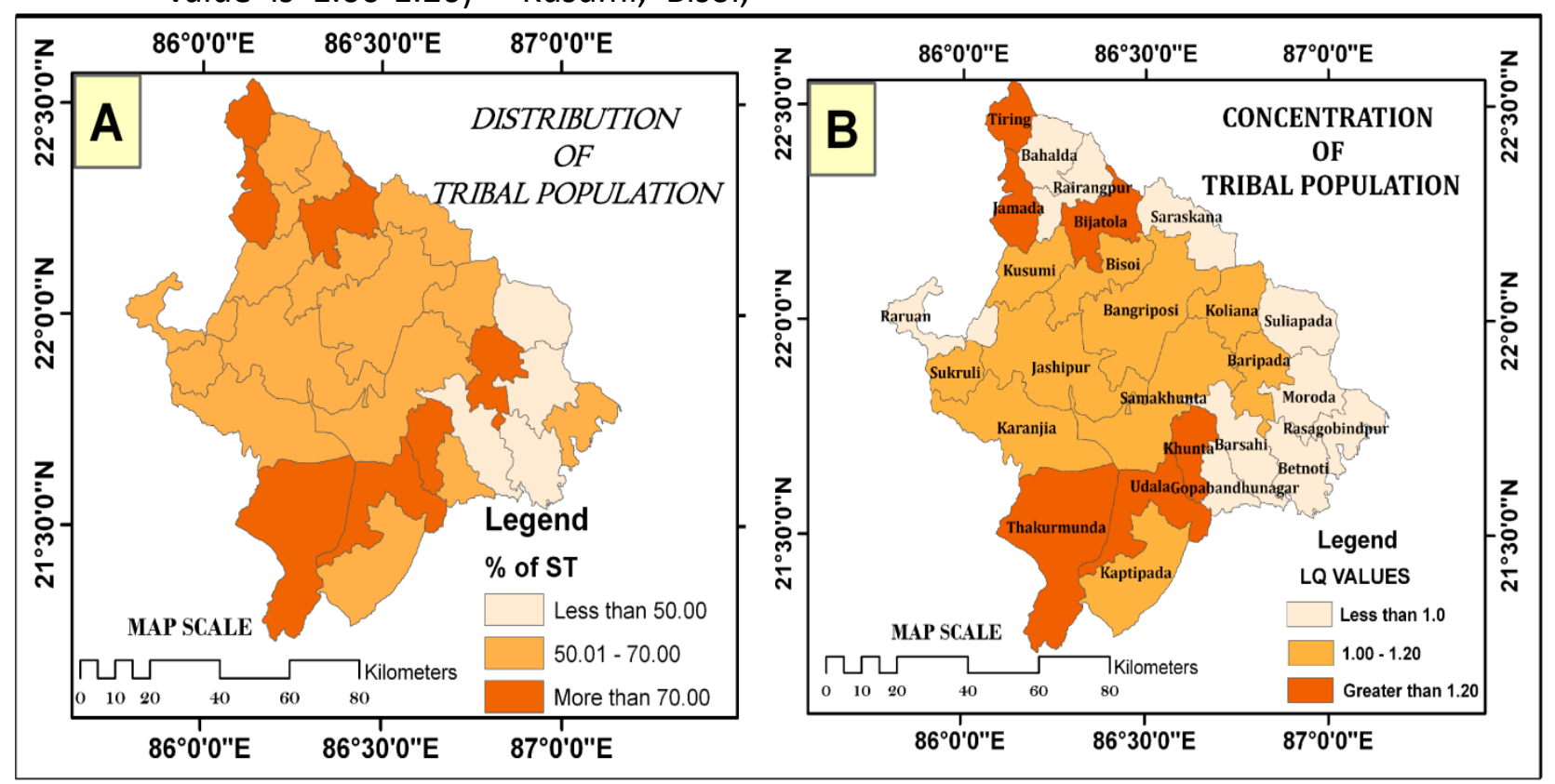

Fig. 3A and 3B: Block-wise Distribution \& Concentration of Tribes in Mayurbhanj (Data Source: Census of India 2011, Calculation \& Mapping by the Authors)

\section{Literacy Status of Mayurbhanj}

Literacy rate is considered as one of the crucial indictors of education. The overall literacy rate in Orissa has increased by about 57 (\%). That is, between 1951 and 2011, it increased from 15.8 percent to 72.03 (\%) (Fig. 4/B). This rate of increase is roughly the same for all-India. However, as per the 2011 Census, Orissa still ranks 25th among 35 states/Union Territories (Census of India, 2011). However, the literacy rate of Mayurbhanj is still far behind than state and national average. The overall literacy rate in Mayurbhanj was very low in the immediate

\footnotetext{
3 To find out Disparity between two groups we use 'Sopher's Disparity Index'. This method of calculating disparities has been developed by David V. Sopher (1974) modified by Kundu and Rao (1983) as the original index fails to satisfy the additive monotonocity axiom (The additive monotonocity axiom specifies that if a constant is added to all observations in a non-negative series, ceteris
}

post-independent era. In 1951 , only $5.2 \%$ people in the district were literate, among them male literates were $9.6 \%$ while female literates were only $1.2 \%$. With governmental efforts (for example, Sarbasikhsha Abhiyan, Mid-Day Meal Scheme, etc.) for expansion of basic education, the literacy rate in the district increased to 63.17\% in 2011 (Fig. 4/A), while male and female literacy rates stood at $73.76 \%$ and $52.71 \%$ respectively. Though the Sopher's Disparity Index ${ }^{3}$ reveals that the overall educational disparity, our findings suggest that the gender

paribus, the inequality index must report a decline) (Husain, 2010) . According to this method:

$\mathrm{DI}=\log (\mathrm{X} 2 / \mathrm{X} 1)+\log [(\mathrm{Q}-\mathrm{X} 1) /(\mathrm{Q}-\mathrm{X} 2)]$

Where, $X 2>X 1$ and $Q=200$. In this method, $X 2$ is taken for the variable having comparatively higher value and $X 1$ for the lower value. According to this Index, in case of perfect equality i.e. no disparity at all, the value of DI (Disparity Index) will be 'Zero'. 
gap in literacy have been decreasing over time (Fig. 4/B).

\section{Block-wise Spatial Disparity in Literacy Rate}

In 2011, the state average of male literacy rate stood at $81.59 \%$ and female literacy rate stood at $62.46 \%$ in Orissa. The male literacy rates in the blocks of Mayurbhanj ranges from $51.59 \%$ in Thakurmunda to $69.43 \%$ in Gopabandhu Nagar block, while the female literacy rate ranges from $24.68 \%$ in Thakurmunda to $47.69 \%$ in Gopabandhu Nagar. This signals that the highest rural female literacy rates are not even equal to the lowest male literacy rate, which indicates that overall female literacy rates are lagging behind their male counterpart in the rural blocks of Mayurbhanj. Even Bijatola, Jashipur, Baripada, Thakurmunda, Kaptipada and Udala blocks represent less than $60 \%$ male literacy (Fig. 5/A). Among these blocks, three are tribal concentrated (Kaptipada, Udala and Thakurmunda). In spite of an urban area, the cause of low male literacy in Baripada is the immigration of worker from the western and border areas of Mayurbhanj. In case of female literacy, more than $40 \%$ female are literates only in three blocks namely Gopabandhunagar, Barsahi and Betnoti (Fig. 5/B).

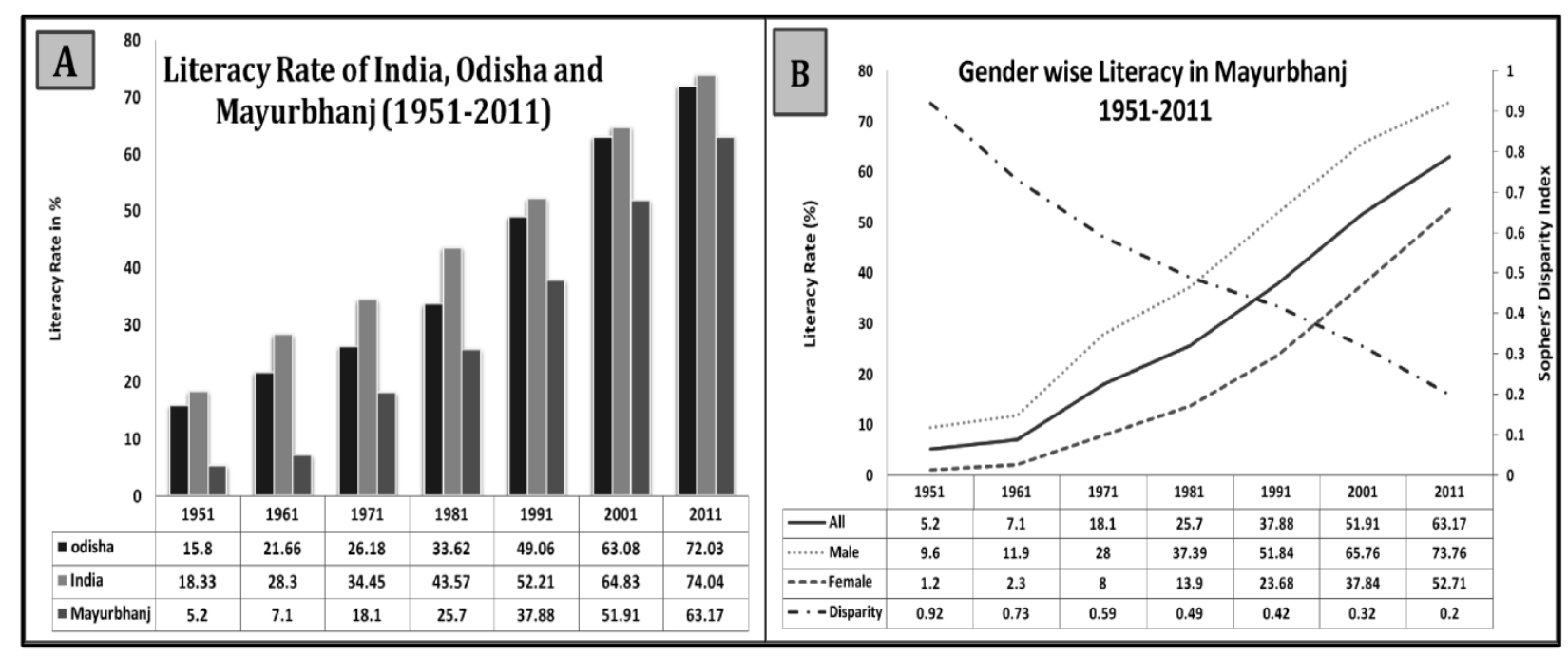

Fig-4: Status of Literacy

(Data Source: Census of India, Figures: Authors)

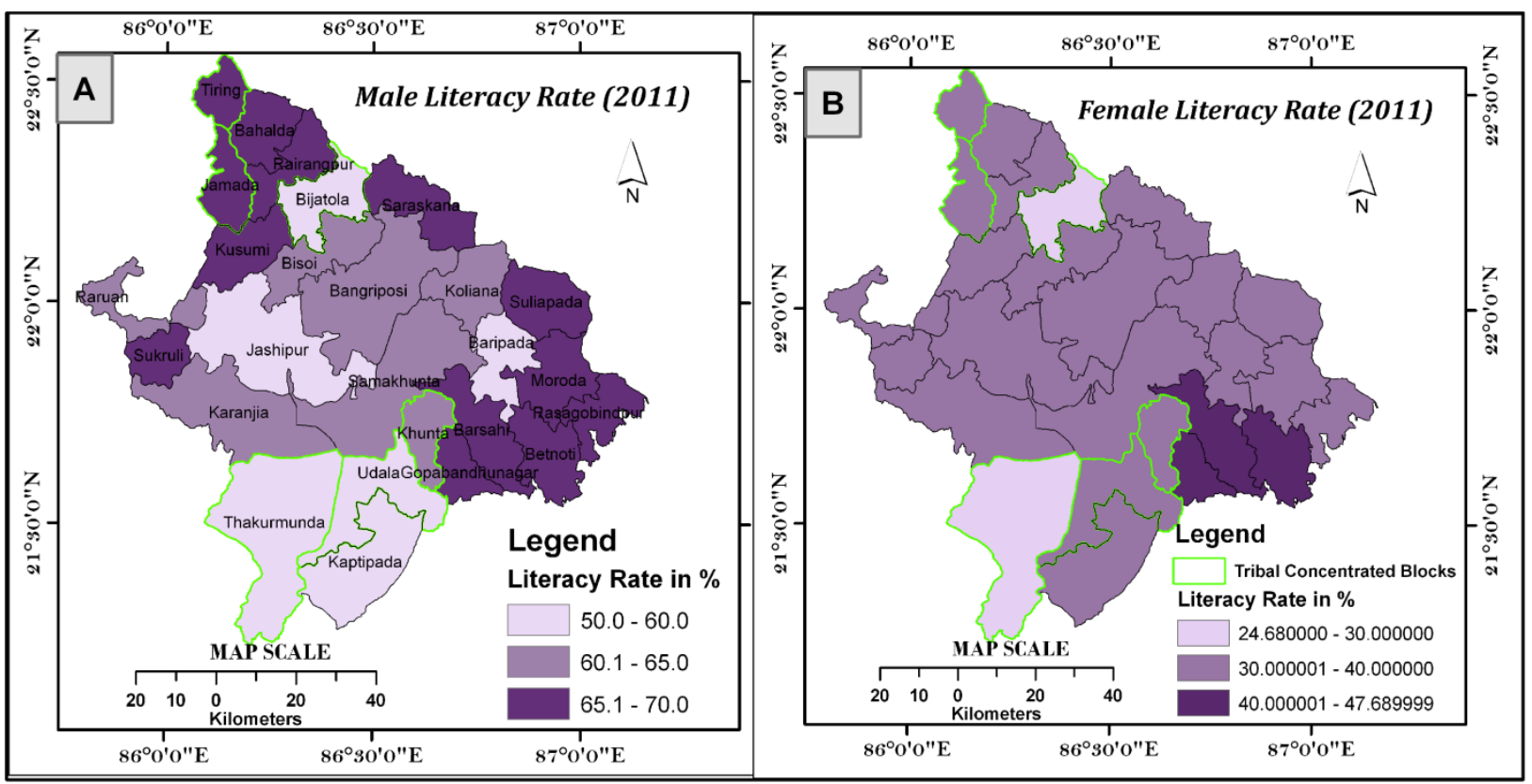

Fig.-5: Gender-wise Literacy rate (Data Source: Census of India 2011, Figures: Authors) 


\section{Educational Disparity between Tribes and Others}

The literacy rate of Scheduled Castes (SC) population is almost same as the general castes. The literacy rate of SC in 2001 was $53.56 \%$ as compared to $51.91 \%$ for all. However, overall the ST population was less literate than SC and General category with literacy rate of $38.80 \%$ in 2001. According to the values of Co-efficient of Equality ${ }^{4}$ in primary education, Thakurmunda and Jashipur have high educational disparities between STs and Other category of population. The Co-efficient value of maximum blocks is more than 75 , which indicates that the overall educational disparities between tribes and others are very low in case of primary education (Fig. 6/A). However, in the case of higher education, the value of co-efficient of equality is very low in Bijatola, Bisoi, Baripada, Barsahi, Udala and in Kaptipada, which indicates that in these blocks, tribal communities lag behind their counterparts. In the blocks of Mayurbhanj, the Co-efficient value of higher education in maximum blocks ranges from 7 to 54 (except Bahalda), which indicates that the overall educational disparity between the tribes and others are high in case of higher education (Fig. 6/B).

\section{Block- \& Gender-wise Educational Disparity}

Illiteracy of women in this district continues to be a major problem. But, the Sopher's gender disparity index for literacy in the district has registered a decline from 0.92 in 1951 to 0.2 in 2011, which indicates the overall educational disparity amongst gender have been continuously decreasing over time (Fig. 4/B). However, gender-wise literacy rates between different blocks in Mayurbhanj indicates that Bisoi, Tiring, Jamadaand Bijatola blocks have high educational disparities amongst gender according to Sopher's Disparity Index (Fig. 7).
Among these four blocks, Tiring, Jamada and Bijatola blocks are tribal-concentrated blocks, which means that the literacy rates of females belonging to Scheduled Tribes (ST) continues to be a major problem in this district. Although, the overall school enrolment increased with time, which was also an aim of the Millennium Development Goal of universal primary education, but there is a remarkable gap between boy's and girl's enrolment in school education.

\section{Health Status of Mayurbhanj Compared to Other Districts of Orissa}

As mentioned earlier, Orissa has the second largest tribal population in India next to Madhya Pradesh. In percentage, it has the highest tribal concentration in its population. The state occupies one of the lowest positions in the country in terms of the level of development. In 2011-12, over $32.6 \%$ of the population lived below the poverty line as against $21.9 \%$ at the national level (Rangarajan, 2014). If human development is viewed as the process of widening the choice of people as well as the achieved levels of their wellbeing (Patra, 2009), the situation is far worse in the tribal districts. Human development and health indices of tribals are very low in Orissa, particularly in the tribal dominated districts. In 2007-08, Human Development Index (H.D.I) of Orissa is 0.362 , which is much lower than the H.D.I. of India (0.467) and many other states as per the Human Development Report, 2011. Seven among the nine tribal districts of Orissa hold 24 to 30 H.D.I. ranks. However, as reported in Orissa Human Development Report 2004, the Human Development Index of 0.639 for Mayurbhanj is much better than the state and the district occupies ninth place among the thirty districts of the state (Fig. 8/A).

\footnotetext{
${ }^{4}$ To measure the educational disparity between different ethnic groups we use 'Co-efficient of Equality in Education'. Victor S. D'Souza (1980) evolved this formula for the measurement of educational inequalities among Scheduled Caste of Punjab. The coefficient of equality is estimated by using the following formula:

$\mathrm{Q}=[((\mathrm{Et} / \mathrm{Eo})) /((\mathrm{Pt} / \mathrm{Po}))]^{*} 100$

Where $Q=$ Coefficient of equality for STs, Et = Enrolment of Scheduled Tribes in any particular types of education, Eo
}

$=$ Enrolment of other communities in the same, $\mathrm{Pt}=$ Population of Scheduled Tribes, $\mathrm{Po}=$ Population of other communities. If the value of co-efficient of equality is 100 , it indicates that Scheduled Tribes are at par with other communities and availing the same facility of education like others. If it is less than 100, it indicates that the tribal communities are lagging behind their counterparts. This would provide us the educational status of Scheduled Tribes vis-a-vis Non Scheduled Tribes (Das and Sahoo, 2012). 


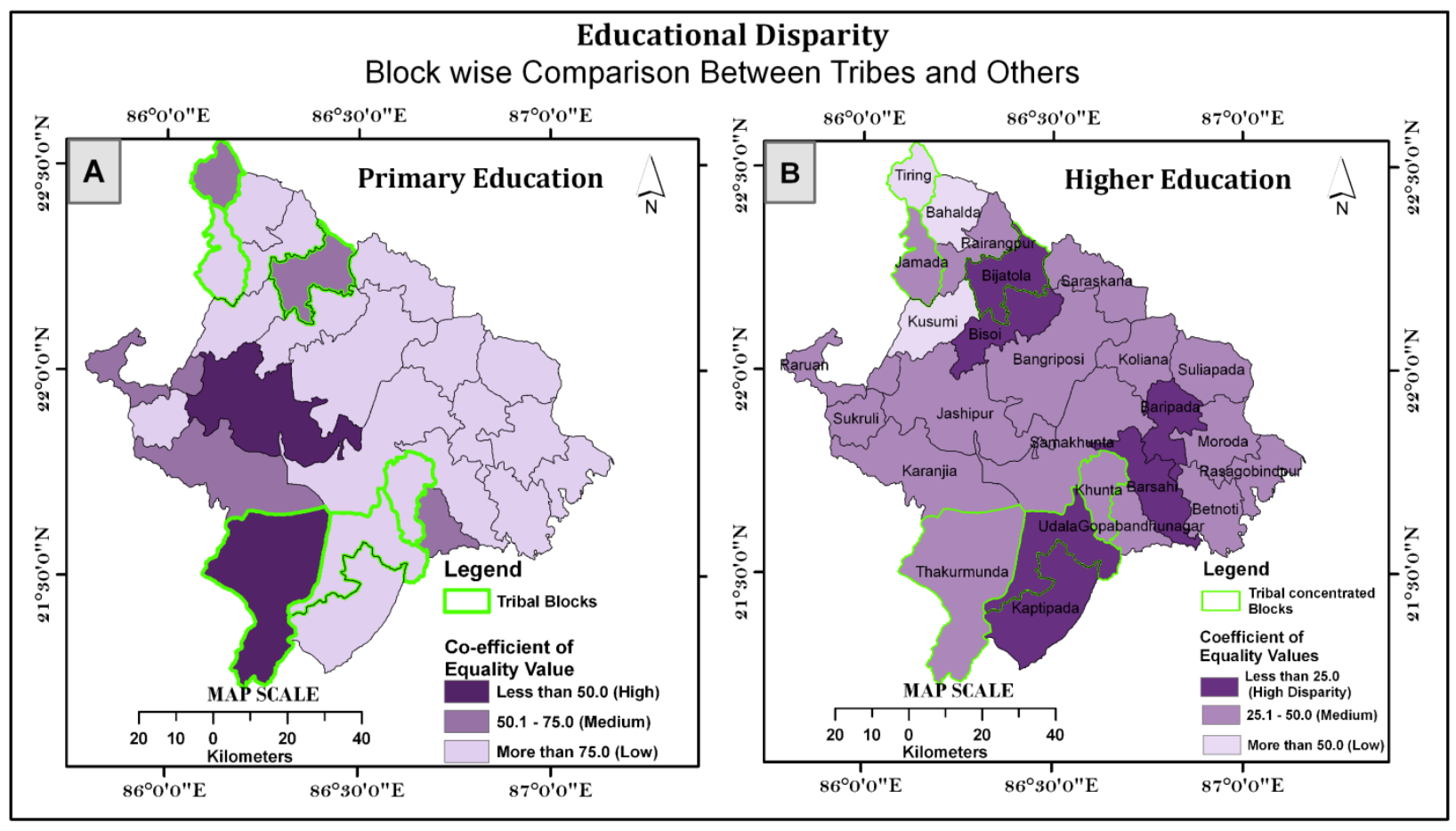

Fig. 6: Co-efficient of Equality in Education

(Source: ST \& SC Development, Minorities \& Backward Classes Welfare Department;

Calculation \& Mapping by the Authors)

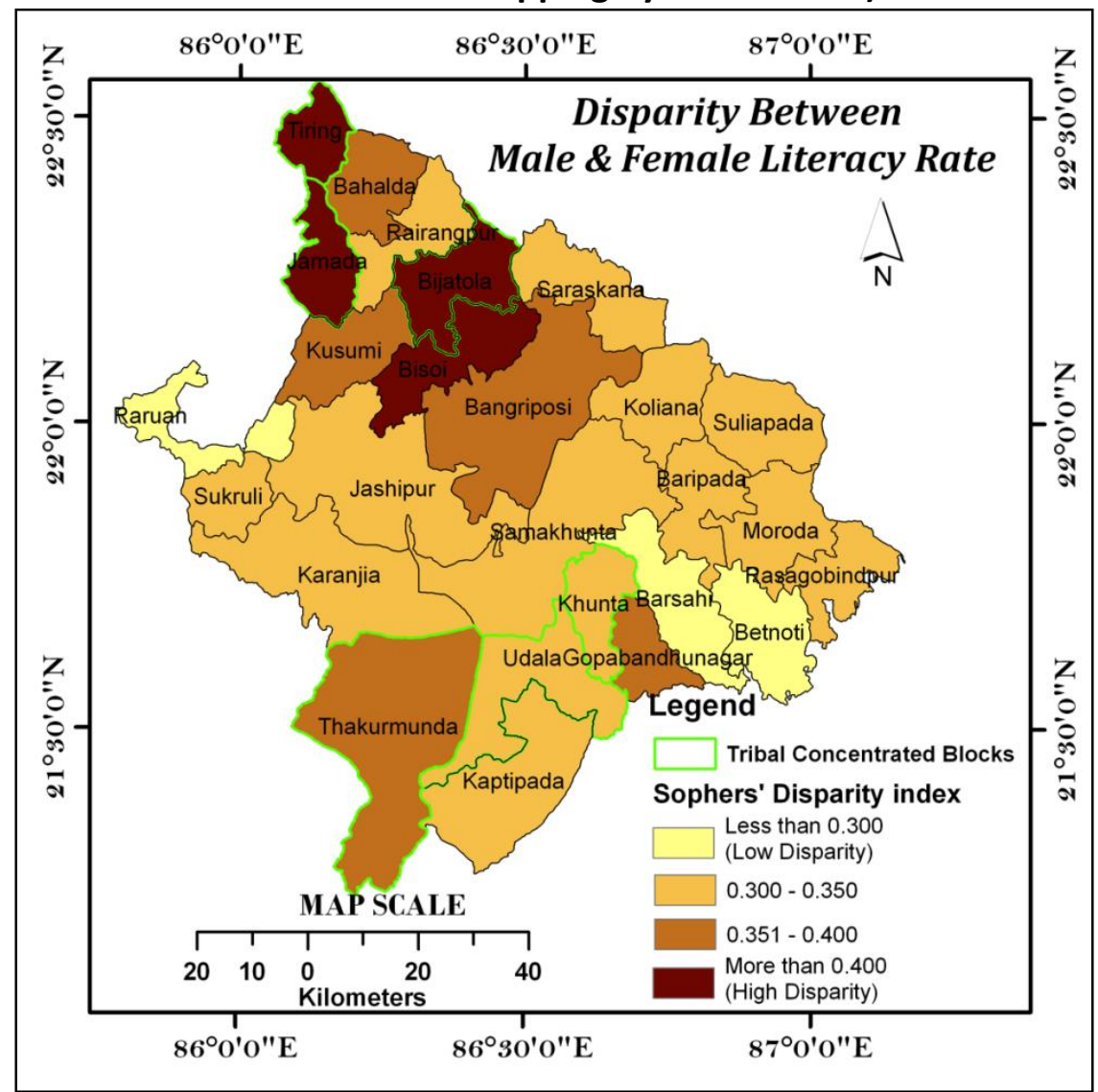

Fig. 7: Block- and Gender-wise Disparity in Literacy

(Data Source: Census of India 2011, Calculation \& Mapping by the authors) 


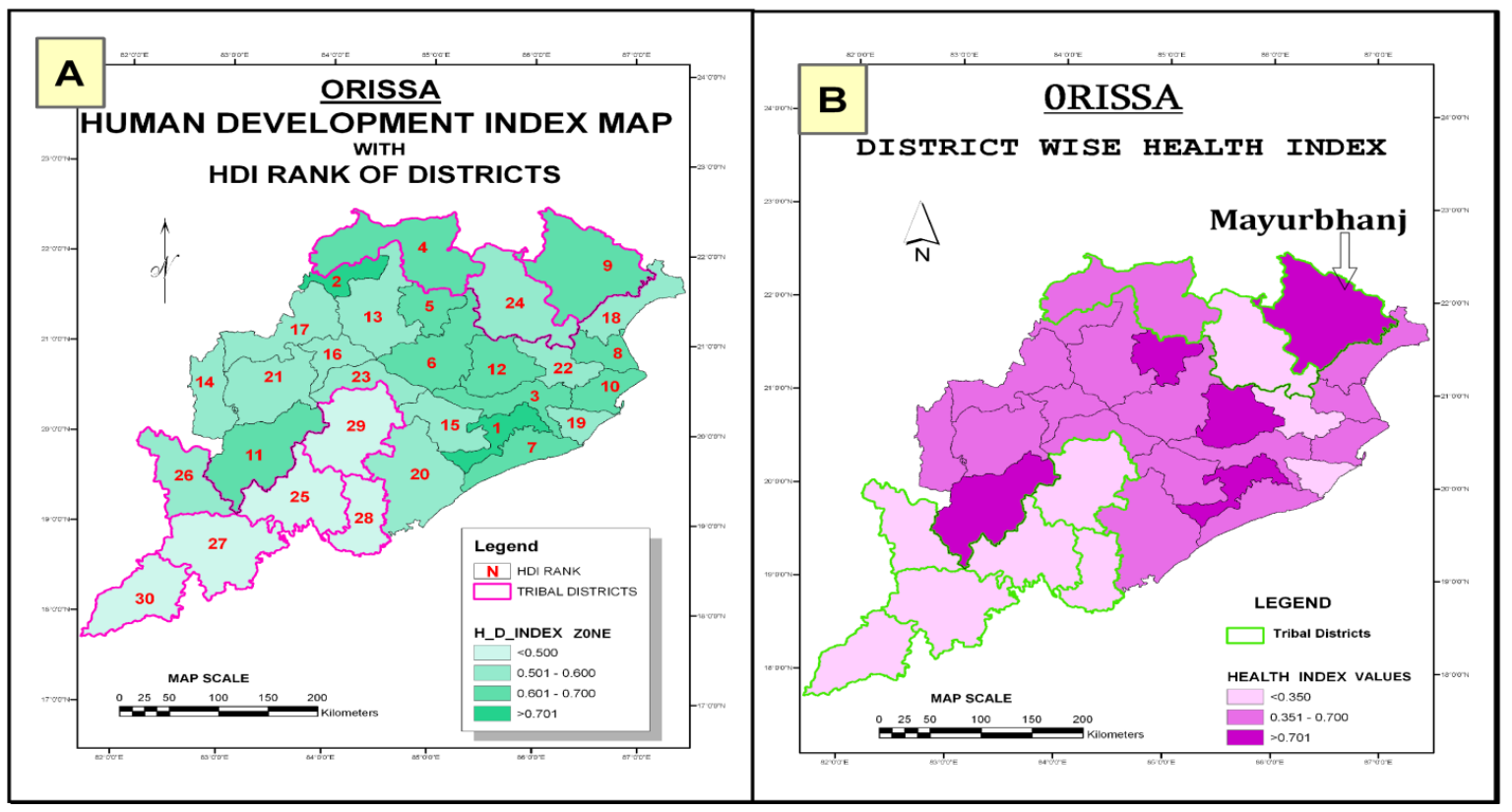

Fig. 8A \& 8B: Mapping of HDI and HI of Orissa

(Data Source: Human Development Report, Orissa (2004), Figures: Authors)

An overall picture of the health status of a region is indicated by its recent demographic changes. According to Orissa Human Development Report 2004, a slower growth rate of population in Mayurbhanj compared to the state between 2001 and 2011 gives a relatively good picture of health status in the district. As mentioned in this report, the Health Index of Mayurbhanj is of 0.782 , which is higher than 0.471 for the state and the district occupies first place among the districts of the state (Fig. 8/B). This indicates relatively good picture of health status in the district.

\section{Diversity of Health Status within Mayurbhanj}

Although the Human Development Index and Health Index of Mayurbhanj represents relatively good picture comparing with other districts but there are also variations between health status within administrative and social level. For example, the Infant Mortality Rate (IMR) of total Mayurbhanj district was lower than national-level average (66/1000 live births) in 2001. But among twenty-six blocks of Mayurbhanj only six have higher IMR than national average (Fig. 9/A) and Udala's (tribal concentrated block) Infant Mortality Rate is more than average of Orissa (91/1000 live births). Though as whole, the IMR for the district, which was 97/1000 live births in 1997 declined to 42.03/1,000 live births in 2009 . Despite this, the health scenario in Mayurbhanj leaves much to be desired. The challenge is to reach out to vulnerable tribal groups who live in remote and poorly accessible areas (DHDR, Mayurbhanj 2011). One of the major health related problems in Mayurbhanj is Child malnutrition. As per the RCH-2 Survey (2004), about $48 \%$ children in Mayurbhanj were found to be underweight and $17.80 \%$ were severely underweight.

Fig. 9/B shows block wise status of malnourished children. From obtained data from Office of the Chief District Medical Officer and District Social Welfare Officer (CDMO \& DSWO), Mayurbhanj, it is clear that in all the blocks more than half of the rural children between 0-6 years were reported as malnourished. Only in four blocks less than $55 \%$ children and in eight blocks more than $60 \%$ children are suffering from malnourishment. It is also clear that among the six tribal Blocks, four blocks (Tiring, Bijatola, Udala and Thakurmunda) have high percentages of malnourished children. Providing adequate antenatal care for healthy motherhood and childbirth is one of the Millennium Development Goals of Orissa as well as of Mayurbhanj. Data on inter-block full antenatal care of pregnant women (\%) in the district represent inadequate 
health picture (Fig. 10/A). In 2008, the proportion of pregnant women receiving full ANC (antenatal care) in Mayurbhanj was $24.25 \%$ (DHDR, Mayurbhanj 2011). Among twenty-six blocks of Mayurbhanj the condition of Koliana, Sukruli and Suliapada is worst in terms of ANC. The full ANC among pregnant women in these three blocks is very low i.e. below $20 \%$. Only in two blocks, above $30 \%$ women received full ANC during their pregnancy, one is Karanjia (31.13\%) and other block is Jashipur (30.23\%). Though comparatively large proportion of births (67.2\%) took place at home in the district of Mayurbhanj but there are also huge variations among the blocks. Interaction with people in Focused
Group Discussions (FGDs) during the sample survey of DHDR (District Human Development Report) showed, in rural areas the proportion of institutional deliveries was as low as $52.91 \%$. On the other hand the value was quite high (i.e., more than 99.64\%) in urban areas (DHDR, Mayurbhanj 2011). From District Human Development Report of Mayurbhanj, 2011, it is clear that block wise institutional delivery varies from $4.64 \%$ in Samakhunta to $79.32 \%$ in Barasahi block (Fig. 10/B). In Samakhunta block, low institutional deliveries stems from the lack of transport facilities due to presence of rugged topography and dense vegetation.

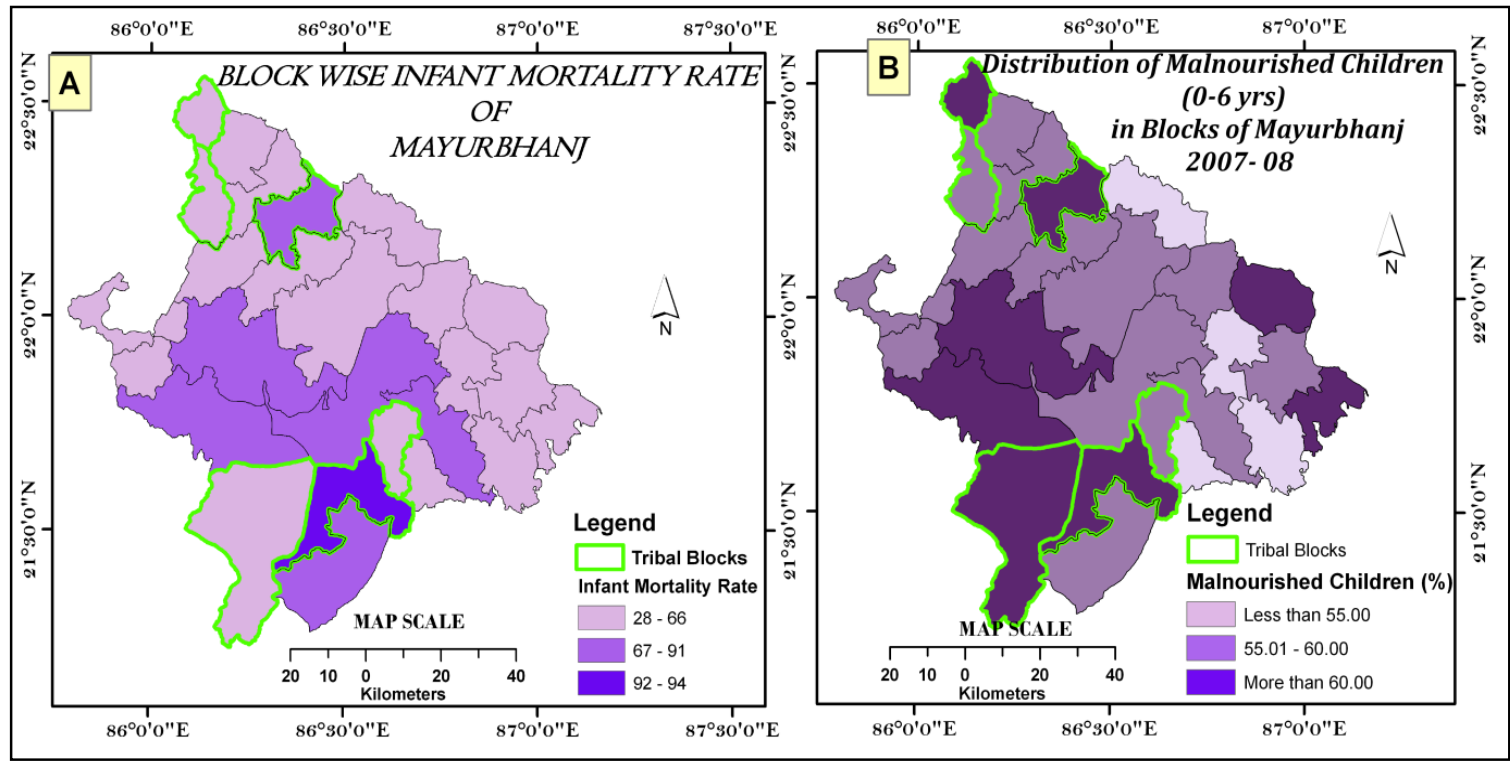

Fig-9A \& 9B: Block-wise IMR \& Distribution of Malnourished Children in Mayurbhanj (Data Source: DLHS-3, Figures: Authors)

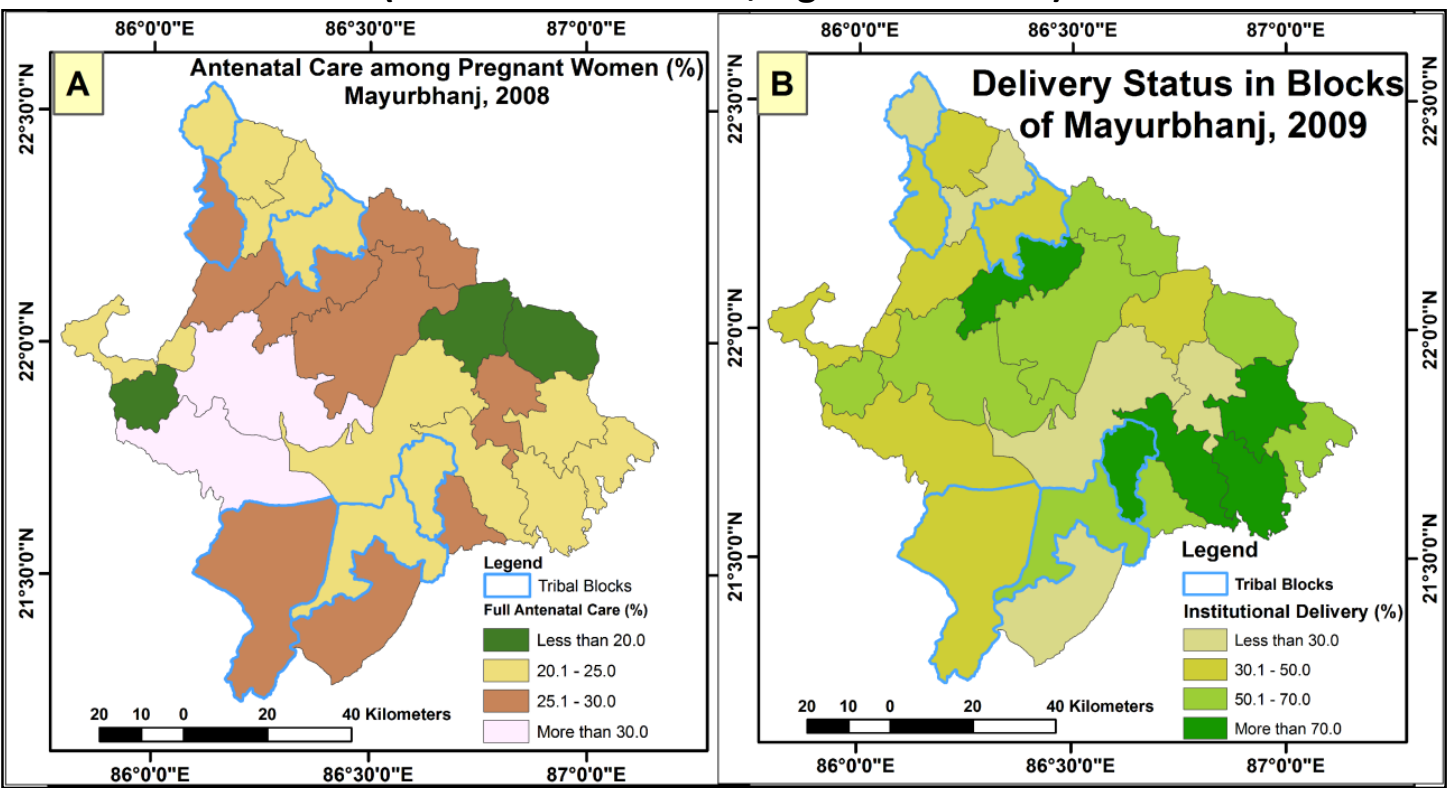

Fig-10A \& 10B: Inter-Block variations of Antenatal Care and Delivery Status in Mayurbhanj (Data Source: DLHS-3, Figures: Authors) 


\section{Economy of Orissa and Mayurbhanj}

Economic growth is not enough for human development, but it is a necessary condition. The cost of living in rural Orissa is one of the lowest in the country and the cost of living in urban Orissa is even lower than the rest of India. In terms of real per capita income, the State has lagged behind the national average ever since independence. In 1950-51, Orissa's real per capita income was about 90 percent of the national average, but in 2012-13, it came down to about 75.6 percent of the national average (Odisha Economic Survey, 2014-15). Figure 11 gives the dynamics of the composition of Odisha's economy from the year 2004-05 to 2011-12. It is clearly becoming less agricultural, more industrial and more service-oriented over time. In 2013-14, agriculture represents only 15.58 percent of Orissa's GSDP. The Service Sector and industry sector represent 59.02 percent and 25.4 percent respectively.
On the other hand, the tribes of Mayurbhanj are almost dependent mainly on cultivation. Some people are engaged in mining activities. People are also engaged in hunting, collecting minor forest produce (MFP), rural handicraft, handloom textiles, village and cottage industries such as pottery, sal leaf plate and cup making, stone carving and handicrafts for their sustenance. From Net District Domestic Product (NDDP), we can get an idea about material livelihood conditions of the district. In the income indices prepared for 30 districts in Orissa Human Development Report 2004, Mayurbhanj ranked 21st, indicating that it was a low-income district. Per capita income of the district has been consistently lower than the state average income and has declined as a proportion of the latter from $89 \%$ in $1993-94$ to $73 \%$ in $2004-05$. According to the Directorate of Economics and Statistics, Orissa, the gap between the two increased from ₹527 in 1993-94 to ₹4,478 in 2004-05 (Fig. 12).

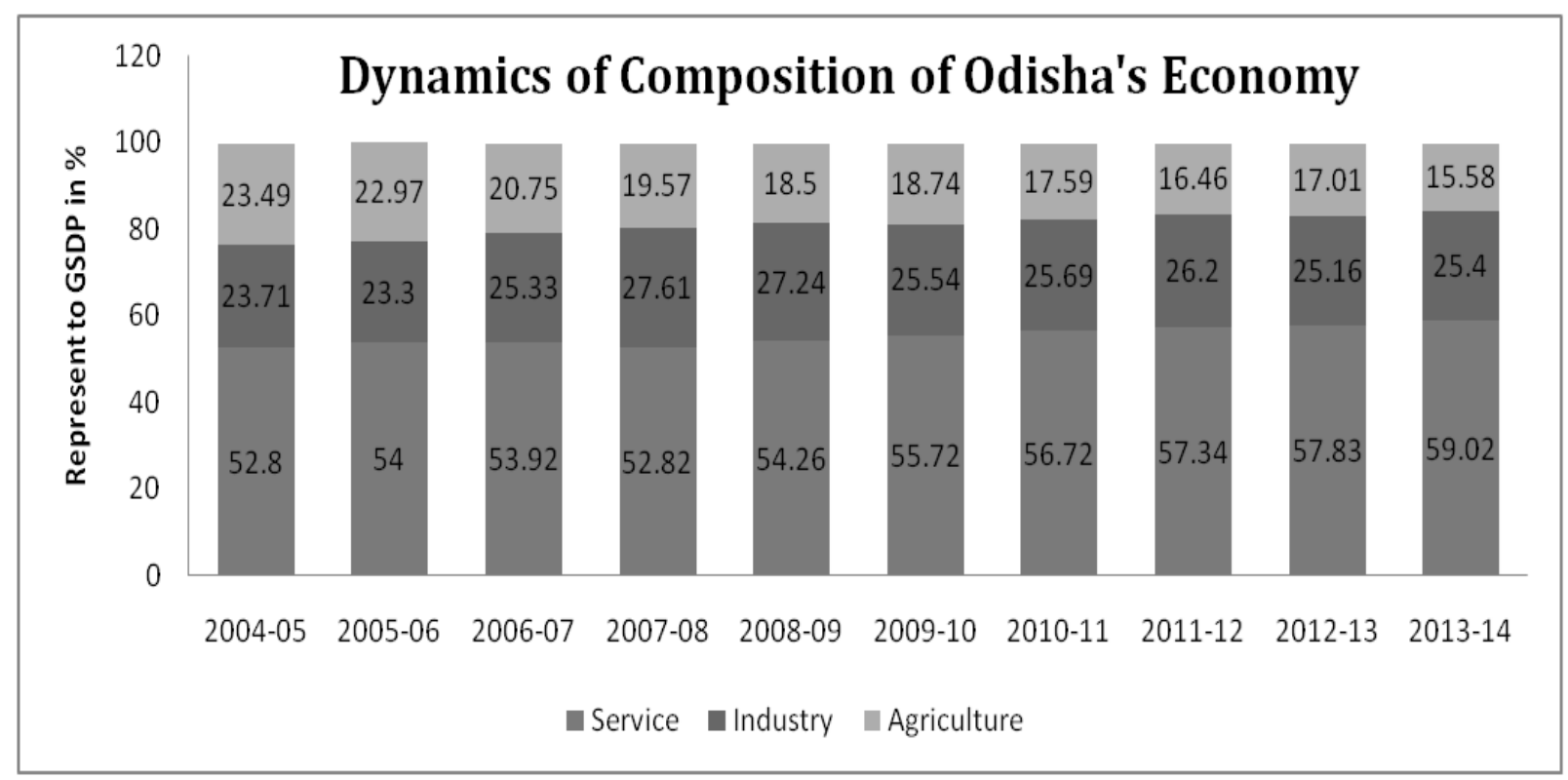

Fig. 11: Dynamics of Composition of Orissa's Economy Data Source: Odisha Economic Survey, 2014-15 


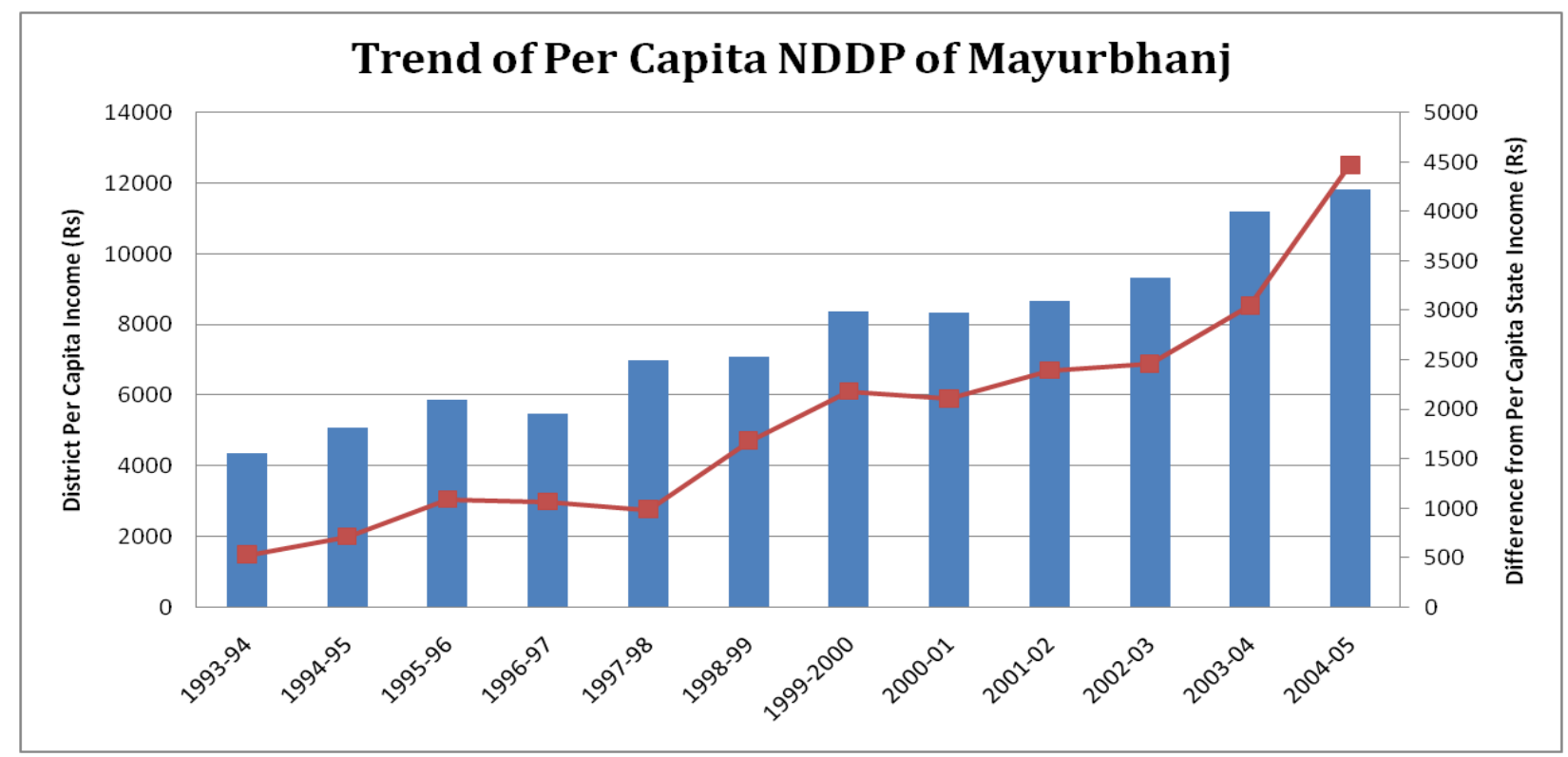

Fig-12: Temporal Changes of Per Capita NDDP of Mayurbhanj

Data Source: Directorate of Economics and Statistics, Orissa

\section{Workforce Participation Rate}

The issue of livelihood security is closely linked to employment status of the people. As per the 2001 Census, the Work Participation Rate (WPR) in Mayurbhanj was $46.23 \%$. With the control of birth rate, the value reaches up to $60 \%$ in 2011. The proportion of main workers in the total workforce increased from $80.09 \%$ in 1981 to $81.36 \%$ in 1991 , but decreased to $60.17 \%$ in 2001. Due to unemployment in 2011, the proportion of main workers to total workforce decreased to $43.75 \%$, which represent an alarming condition of the economic development of the district. In Mayurbhanj, the
Work Participation Rate (WPR) in different blocks ranges from $46.3 \%$ to $68.9 \%$. Figure $13 / \mathrm{A}$ shows block wise main worker's percent to total population and Figure 13/B represents nonworker population in the blocks of Mayurbhanj. It may be observed from the figure that the percentage of non-worker population is high in the western-bordered blocks Jamada, Sukruli, Bahalda, Tiring, etc. Absence of urban centre, unfavourable physiographic conditions, etc. is the underlying causes for the same. This increasing unemployment results in the emergence of Maoist movement in the westernbordered blocks.

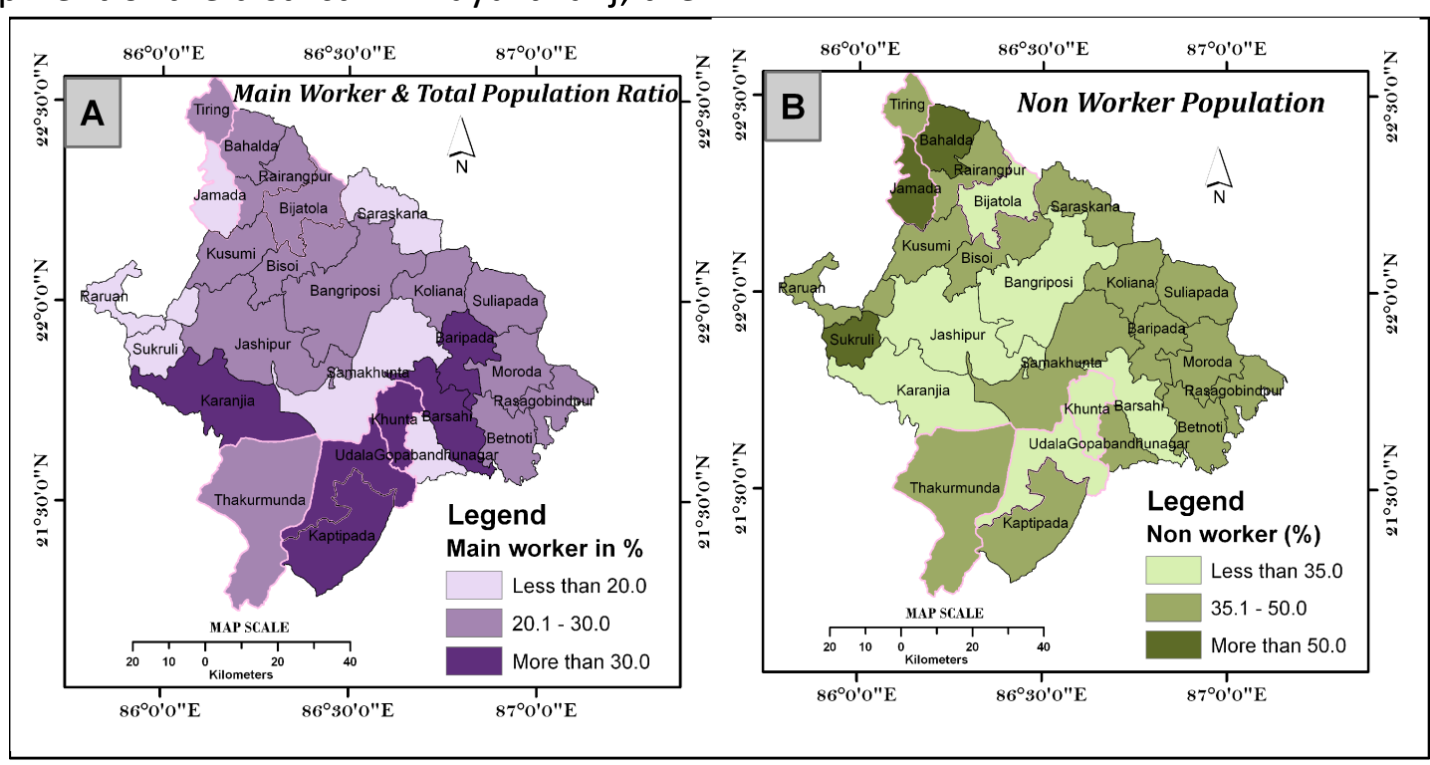

Fig-13A \& 13B: Main Worker's to Total Population and Non-Worker Population in Blocks of Mayurbhanj Data Source: Human Development Report, Orissa (2004), Figures: Authors 


\section{Dominant Economic Activity}

Based on the percentage of different types of workers, we have tried to identify the dominant economic activity and its level in different blocks. In this regard, we have used Nelson's Method $^{5}$ to identify dominant functions. According to this method, for example, if percentages of cultivator of a particular block leave behind the overall mean plus standard deviation value, then it will treat as cultivator dominant block. If the value surpasses the overall mean plus three standard deviation values then its category will be CL3 or the block's economy is highly depended on Cultivation. If the percentage of different types of worker (that is, Cultivator, Agricultural Labours, Household Industry Worker and Other Worker) did not cross the overall mean plus standard deviation value, then it will be a Block with diversified economy.

According to this method, the economy of maximum blocks in Mayurbhanj is diversified or depended on mainly Cultivation (Table 1). Only four blocks' (Baripada, Karanjia, Rairangpur and Betnoti) economy mainly depends on Services as these blocks have urban centres. Among the six highly tribal dominated blocks, Jamada and Tiring's maximum people are Cultivators, which indicates the lower economic condition. Figure 14 on Dominant Economic Activity also indicates that maximum Cultivator Blocks are situated in western part of the district, which means the western part of Mayurbhanj is highly backward.

\section{Suggested Measures to Overcome the}

\section{Problems of Socio-Economic Development}

Enriched with various natural resources, Mayurbhanj, at present, is one of the largest districts in Orissa. However, it has not yet been developed as expected. Physical barriers and inadequate infrastructural facilities like road communication, railway links, telecommunication facilities, lack of education using modern technology, etc. are the identified as constraints for setting up large industries. For proper 'growth with equity and social justice' (which has been the development agenda of developing countries for many decades) of Mayurbhanj as well as of Orissa, an educated developed society is needed to enhance capabilities of the tribes to participate in the mainstream economic development.

The research suggests that all the tribal dominated districts of Orissa (including Mayurbhanj) suffer from different dimensions of poverty. That is why the basic services and needs like availability of nutrition, supply of pure drinking water and sanitation facilities should adequately be provided towards improving their socio-economic conditions. Commercial promotions of tribal art will help them to improve their economic conditions. For appropriate development of socio-economic conditions, there is an urgent need for HDI mapping through rating and approach. Based on backwardness value, budgetary allocations by the government are required for the overall development of the area. The common people (including the tribals and those living below poverty line) should be made aware about the existing facilities so that they can utilise the facilities for their development. In this regard, a mass awareness campaign on development programmes need to be organised at regular intervals in the tribal areas. For this, the government should collaborate with NonGovernment Organisations.

\footnotetext{
5 Harris (1943) made the first attempt towards identification of the dominant economic characteristics of an area. H. J. Nelson (1955) used almost similar method with a threshold which could be worked out from the mean and standard deviation (SD) of the occupationa structure of a given area. According to Nelson's method first percentages of each occupation to the total labour force of the area are worked out for each unit area. The
}

mean and SD of these percentage among all the unit area are then calculated separately for each occupation. The areas are then classified according to their percentage of each occupation being more than or equal to mean $+\mathrm{SD}$, mean $+2 S D$, mean $+3 S D$. The percentage of a function less than its mean+SD is not considered as significant (Mahmood, 1977). 


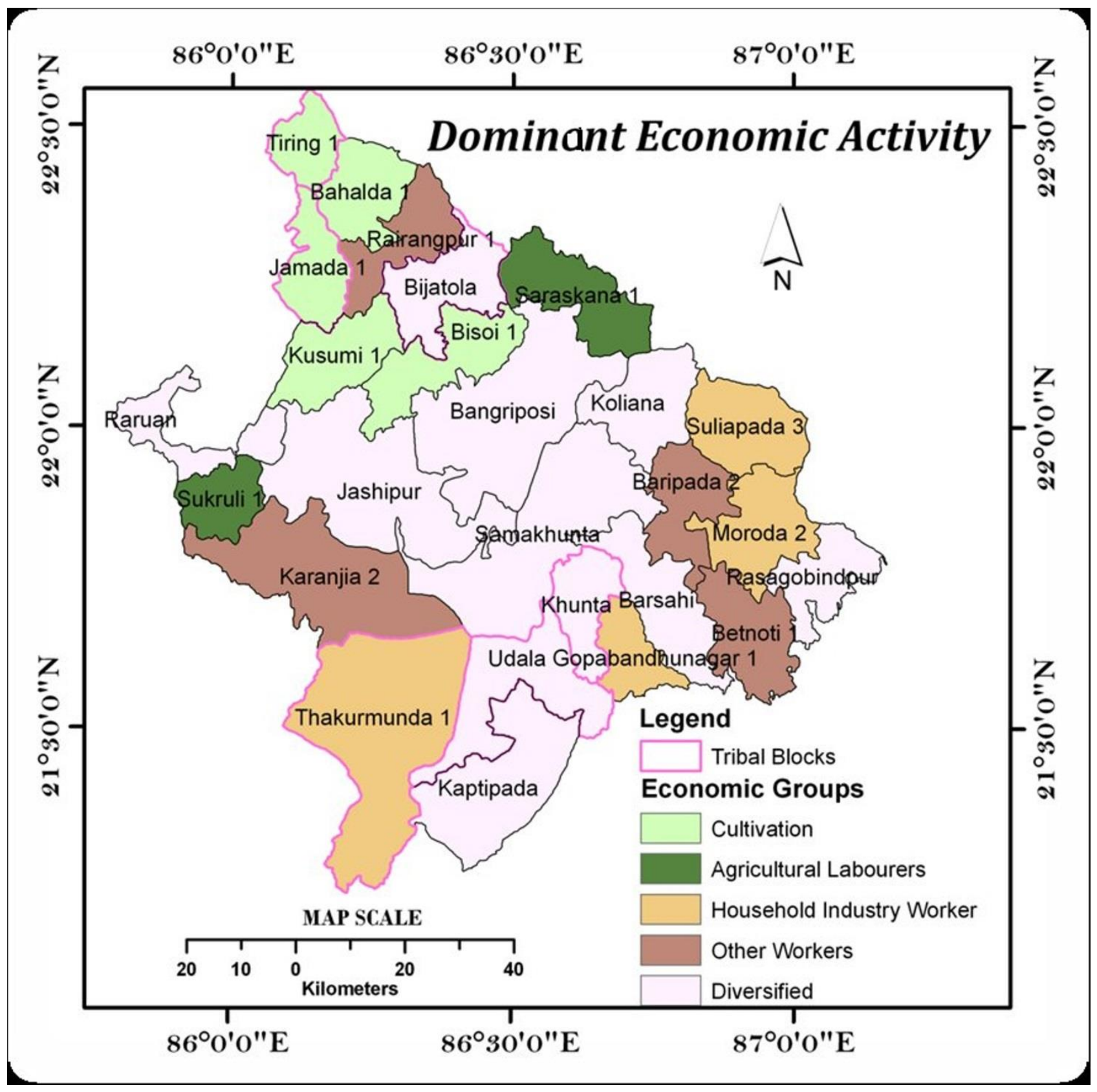

Fig-14: Dominant Economic Activity in the Blocks of Mayurbhanj, 2011 Figures: Authors 
Table 1: Block-wise Dominant Economy Activity of Mayurbhanj, 2011

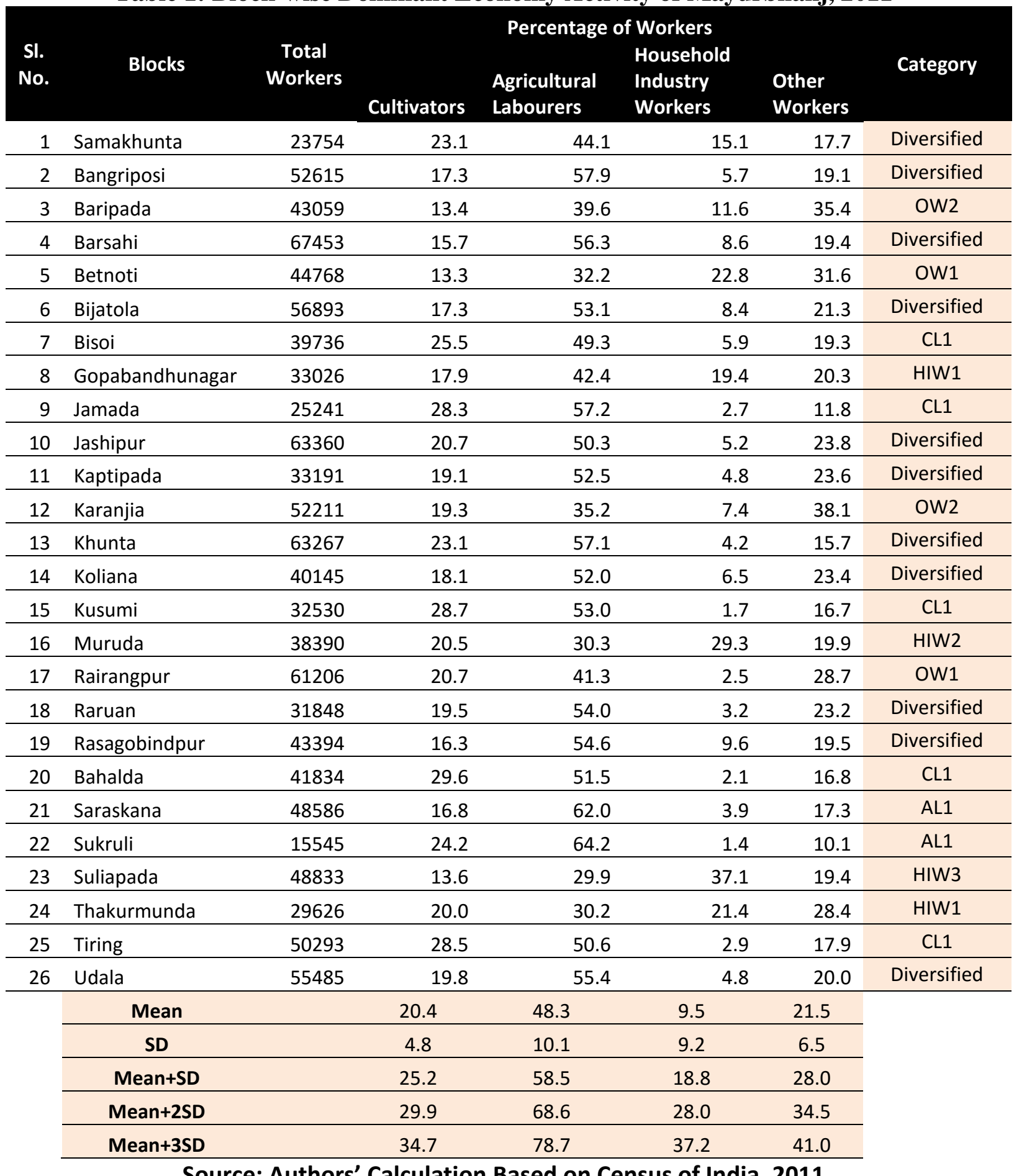

\section{Source: Authors' Calculation Based on Census of India, 2011}

Strong political commitment at the administrative level is urgently needed for providing better services to the communities. Availability of trained, qualified female teachers and developed infrastructure like separate toilets for girls in educational institutes, drinking water, roads, etc. will help to increase the female literacy rates. Adequate infrastructural facilities will help to setting up large industries towards generating employment opportunities.

Finally, it may be mentioned that an improved educational infrastructure in spatial scale is desirable. Otherwise, rapid economic growth of the district and state will be discontinued, and tribes would remain the most neglected section 
of the society. Under this situation, spread of education and promotion of tribal art and craft is essential for the social and economic development of tribes.

\section{References}

Agarwal S (2013). Disadvantageous Situation of Tribal Women and Children of Orissa, India: A Special Reference to Their Health and Nutritional Status. Journal of Community Nutrition \& Health, Vol.2 (1).

Basu S. (1994). A Health Profile of Tribal India. Health for the Millions. 2:124.

Census of India Report (2013) Ranking of States and Union Territories by Literacy Rate:

2011, downloaded from http://censusindia.gov.in/2011-prov results/data_files/india/Final_PPT_2011_chapt er6.pdf on 28.11 .2014

Das A. B. \& Sahoo D. (2012): Regional Disparities in Education: A Comparative Study between Kbk and Non-Kbk Districts of Odisha, India. International Journal of Humanities and Social Sciences Vol.1: 1, pp. 39-52

Desai S. and Kulkarni V. (2008). Changing Educational Inequalities in India in the Context of Affirmative Action. Demography, Volume 45Number 2, May 2008: 245-270

DHDR (2011). District Human Development Report: Mayurbhanj. Planning and Coordination Department. Government of Orissa. Available at http://phdmaodisha.nic.in/Reports/HDRS/ Mayurbhang-DHDR.pdf (Accessed on 08.08.2014).

District Level Household and Facility Survey of Orissa (DLHS) (2007-08) and International Institute for Population Sciences (IIPS) (2010), Available at http://www.rchiips.org/pdf/rch3/report/OR.pd $f$ (accessed 28.08.2014).

District Statistical Handbook of Mayurbhanj (2009) Prepared by District Planning \& Monitoring Unit, Mayurbhanj, Government of Orissa.

"Educational Safeguards". Department of Education.Government of India. http://web.archive.org/web/20090619063917/ http://www.education.nic.in/cd50years/g/s/l6/ 0SI60301.htm. Retrieved on 27 November 2014.

Harris C. D. (1943): A Functional Classification of Cities in the United States, Geographical Review, vol-33 (1), pp-86-99.

Hassan M. I. and Daspattanayak P.R (2008): Health-Care Infrastructure in Orissa: A Geographical Study, Eastern Geographer, Bhubaneswar, January 2008, Vol. XIV.pp-33-40

Human Development Report, India (2011): Institute of Applied Manpower Research, Planning Commission, Government of India, ISBN-13: 978-0-19-807758-9 ISBN-10: 0-19807758-0. Available from http://www.iamrindia.gov.in/ihdr_book.pdf Human Development Report, Orissa (2004) Government of Orissa, Prepared by Nabakrushna Choudhury Centre for Development Studies, Bhubaneswar 751013, Orissa. Available at http://planningcommission.nic.in/plans/statepl an/sdr_pdf/shdr_ori04.pdf (Accessed on 12.08.2014).

Husain Z. (2010). Gender Disparities in Completing School Education in India Analyzing Regional Variations, Draft dated 24/11/2010: V2.1: Population Research Centre, Institute of Economic Growth, Delhi University

ICMR Bulletin (2003) Health Status of Primitive Tribes of Orissa. Vol-33 (10).October, 2003. Indian Council of Medical Research. New Delhi. ISSN: 0377-4910. Available at http:// icmr.nic.in/BUOCT03.pdf (accessed 08.08.2014).

Kundu, A. and Rao, J. M. (1986). Inequity in Educational Development: Issues in Measurement, Changing Structure and Its Socio-economic Correlated with Special Reference to India. In Raza, M. (Ed.), Educational Planning: A Long-term Perspective (pp. 435-466).

Mahmood A. (1977). Statistical Methods in Geographical Studies, Rajesh Publication, New Delhi. ISBN: 81-85891-17-6, pp. 112. 
National Family Health Survey, India (NFHS-3),( 2005-06) Ministry of Health and Family Welfare Government of India. Prepared by International Institute for Population Sciences, Mumbai.

Available at

http://www.rchiips.org/NFHS/NFHS-

3\%20Data/Orissa_state_report.pdf (Accessed on 18.08.2014).

Nelson H. J. (1955): A Service Classification of American Cities, Economic Geography, vol-31 (3), pp-189-210.

Odisha Economic Survey (2014-15): Planning and Coordination Department, Directorate of Economics and Statistics, Government of Odisha. Available from http://www.odisha.gov.in/pc/Download/Econo mic_Survey_2014-15.pdf

Patra S (2009) Literacy and Health of Tribals in Orissa, Indian Journal of Regional Science, Vol. XXXXI (2).pp. 38-45.

Rangarajan C. P. (2014): Report of the Expert Group to Review the Methodology for Measurement of Poverty, Planning Commission, Government of India. Available from http://planningcommission.nic.in/reports/genr ep/pov_rep0707.pdf

Sopher, D. K, (1980). Sex Disparity in Indian Literacy. In D. E. Sopher (Ed.), An Exploration of India: Geographical Perspectives on Society and Culture (pp. 130-188). New York: Cornell Press.

Sopher, D.K, (1974) "Measurement of Disparity", The Professional Geographer, 26/4, (November), pp. 380-392.

State of the Environment Report - Orissa (2007) available at http://www.moef.nic.in/soer/state/SoEOrissa.pdf(Accessed on 08.08.2014).

Thakur DS, Thakur DC, Saini AS (1991) SocioEconomic Impact of Tribal Development Programmes in Himachal Pradesh. Journal of Rural Development; Vol-10: pp. 823-30.

\section{Acknowledgements}

The authors are grateful to Indian Council of Social Science Research, Government of India, New Delhi for providing financial support for the preparation of the present paper under its sponsored project entitled Tribal Livelihood and Sustainable Development in Mayurbhanj, Orissa. 